\title{
Characterization of ori and parS-like functions in secondary genome replicons in Deinococcus radiodurans
}

Ganesh K Maurya ${ }^{1,2}$ (D), Hari S Misra ${ }^{1,2}$ (D)

\begin{abstract}
The mechanisms underlying multipartite genome maintenance and its functional significance in extraordinary radioresistance of Deinococcus radiodurans are not well understood. The sequences upstream to parAB operons in chrll (cisll) and MP (cisMP) could stabilize an otherwise, non-replicative colE1 plasmid, in $D$. radiodurans. DnaA and cognate ParB proteins bound specifically with cisll and cisMP elements. The $\Delta$ cisll and $\Delta$ cisMP cells showed the reduced copy number of cognate replicons and radioresistance as compared with wild type. Fluorescent reporter-operator system inserted in chrl, chrll, and MP in wild type and cisll mutants showed the presence of all three replicons in wild-type cells. Although chrl was present in all the $\Delta$ cisll and $\Delta$ cisMP cells, nearly half of these cells had chrll and MP, respectively, and the other half had the reduced number of foci representing these replications. These results suggested that cisll and cisMP elements contain both origin of replication and pars-like functions and the secondary genome replicons (chrll and MP) are maintained independent of chrl and have roles in radioresistance of $D$. radiodurans.
\end{abstract}

DOI 10.26508/lsa.202000856 | Received 22 July 2020 | Revised 4 November 2020 | Accepted 4 November 2020 | Published online 16 November 2020

\section{Introduction}

DNA replication and segregation are the highly coordinated macromolecular events required in the growth of any organism (Badrinarayanan et al, 2015). The origin of replication (oric) where chromosomal replication in bacteria initiates is a well-conserved region on chromosomes and comprises of the non-palindromic repeats of 9-mer as DnaA boxes and 13-mer AT-rich repeats (Ogasawara et al., 1985; Marczynski \& Shapiro, 1992; Messer, 2002). In Escherichia coli, DnaA, a replication initiation protein, first binds to the DnaA boxes which subsequently leads to the recruitment of replication initiation complex comprising of DnaB helicase, primase, and DNA polymerase III (Tougu \& Marians, 1996; McHenry, 2011). Earlier, the tripartite genome segregation comprising (i) an origin-proximal cis-acting (pars-like) DNA sequences, (ii) pars binding proteins like ParB or its homologues, and (iii) the P-loop Walker ATPases such as ParA or its homologues has been reported to be the major mechanisms associated with the segregation of duplicated genome into daughter cells (Hayes \& Barillà, 2006). Typically, ParB homologues first bind to the pars-like sequences and the interaction of ParA homologues to ParB-pars complex leads to either polymerization or depolymerization of ParA as required for DNA segregation (Hayes \& Barillà, 2006; Gerdes et al, 2010; Reyes-Lamothe et al, 2012). Among different mechanisms of plasmid/chromosome segregation in bacteria, the diffusion-ratchet model is found to be the most acceptable (Vecchiarelli et al, 2010). Recently, it is shown that the duplicated chromosome segregates into daughter cells by the cumulative actions of different genome maintenance proteins viz. ParA-ParB, SMC (structural maintenance of chromosome)/MukB, topoisomerases, translocases, and nucleoidassociated proteins (Pióro \& Jakimowicz, 2020). Furthermore, it has been observed that the initiation of DNA replication and segregation of duplicated chromosomes occur concurrently (Marczynski et al, 2019). In the majority cases where DNA replication and segregation have been studied, the pars-like sequences are found close to the origin of replication (ori) region. For instance, in Bacillus subtilis and Caulobacter crescentus, the primary pars sequences are located within 8-10-kb from oric (Livny et al, 2007). Furthermore, the genome segregation proteins interact directly with DnaA in many bacteria (Murray \& Errington, 2008; Marczynski et al, 2019). The organization and dynamics of nucleoid during cell growth have been studied in monopartite genome harboring rod- or crescent-shaped bacteria such as E. coli, B. subtilis, and C. crescentus (Esnault et al, 2007; Fisher et al, 2013; Le et al, 2013; Badrinarayanan et al, 2015; Dame \& TarkDame, 2016) and cocci-like Streptococcus pneumonia (Kjos \& Veening, 2017) and Staphylococcus aureus (Morikawa et al, 2006, 2019).

Recently, many bacteria have been reported with multipartite genome system comprising more than one chromosome and large plasmids (Misra et al, 2018). Studies on multipartite genome maintenance in bacteria are limited to Vibrio cholerae, Burkholderia cenocepacia, Rhodobacter sphaeiroides, and Shinorhizobium meliloti (Fogel \& Waldor, 2005; Dubarry et al, 2006, 2019; Galardini et al, 2013). In these bacteria, the proteins of tripartite genome segregation

${ }^{1}$ Molecular Biology Division, Bhabha Atomic Research Centre, Mumbai, India ${ }^{2}$ Homi Bhabha National Institute, Mumbai, India 
encoded on the primary chromosome are phylogenetically similar to the chromosome of monopartite genome-harboring bacteria and found to be different from secondary genome components. Because the sizes of genomic replicons are different, how their replication and segregation are synchronized before cytokinesis would have occurred is intriguing. However, the real-time monitoring of DNA replication in $\mathrm{V}$. cholerae a multipartite genome harboring (MGH) bacteria has shown that replication initiation of different replicons is staggered to terminate roughly at the same time (Rasmussen et al, 2007; Kemter et al, 2018).

Deinococcus radiodurans, a Gram-positive nonpathogenic bacterium characterized for extraordinary radioresistance, also harbors a multipartite genome comprising chromosome I (2,648,638 bp), chromosome II (412,348 bp), megaplasmid (177,466 bp), and small plasmid (45,704 bp) (White et al, 1999). Except small plasmid, all other replicons encode ParAand ParB-like proteins in parAB operons. Earlier, Minsky and colleagues demonstrated that the multipartite genome of this bacterium is packaged in the form of a doughnut-shaped toroidal structure (Levin-Zaidman et al, 2003). Recently, the nucleoid dynamics has been monitored at different stages of growth in $D$. radiodurans and observed that the highly condensed nucleoid adapts multiple configurations during cell cycle progression, and the oric in chrl remains radially distributed around the centrally positioned ter (terminus) sites (Floc'h et al., 2019). The characterization of ori and pars-like sequences in chromosome II (chrll) and megaplasmid (MP), and their localizations in nucleoid have not been reported. Here, we report that the direct repeats located upstream of parAB operons in chrll (cisll) and MP (cisMP) confers both ori and parslike functions. Furthermore, we demonstrate that DnaA encoded on chrl interacts with these cis-elements of secondary genome components, whereas ParB of chrll (ParB2) and megaplasmid (ParB3) shows specific interaction with cognate cis-elements in vitro. Interestingly, both these cis-elements help in the maintenance of an otherwise suicidal plasmid, in $D$. radiodurans. The deletion of cisll ( $\triangle c i s / l)$ and $\operatorname{cis} M P(\triangle c i s M P)$ leads to reduction in copy numbers of respective replicons and the partial loss of $\gamma$-radiation resistance as compared with wild type. These cis mutants produce an increased frequency of cells devoid of cognate replicons. The tetO-TetR-GFP-based fluorescent reporter-operator system (FROS) inserted near the putative origin of replication in chrl, chrll, and MP allowed us to localize these replicons in the nucleoid. Most $\Delta c i s / l$ and $\triangle$ cisMP cells showed the loss of chrll and MP, respectively, whereas there was no change in the wild-type pattern of chrl in these cells. These results suggested that cisll and cisMP confer both ori and pars-like functions, and DnaA encoded on the primary chromosome seems to regulate chrll and MP replication. Nearly no change in chrl localization pattern and its copy number in both the cis mutants, which has affected the maintenance of cognate replicons, further concluded that primary chromosome and secondary genome replicons are maintained independently in this bacterium.

\section{Results}

\section{Sequences in chrll and MP predicted as putative "oriC" and pars-like sequences}

The upstream of parAB operons in chrll and MP contains repetitive sequences similar to the known bacterial "oriC" and pars-like cis- elements. The region spanning between 99 and 544 bp in chrll contain 11 iterons of $18 \mathrm{bp}$ with consensus sequence T(G)CCACAAAGTGCCA(G)CAGG and GC content of $51.6 \%$ was named as cis/l (Fig 1A). Similarly, the region spanning $177,446-417$ bp ion MP contains eight iterons of $18 \mathrm{bp}$ with consensus sequence $C(A)$ CCGCAAAGGTG(A)TCGCTA and 3 iterons of $14 \mathrm{bp}$ with consensus sequence TTTTGACCCCAAAT and GC content of $47 \%$ together named as cisMP (Fig 1B). In addition, both cisll and cisMP elements contain non-canonical putative DnaA boxes which were different from the 13 9-mer DnaA boxes (T(A/G)TA(T)TCCACA) present in the origin of replication of $\mathrm{chrl}$ in $D$. radiodurans and DnaA boxes in oriC of $E$. coli (Messer, 2002; Maurya \& Misra, 2020 Preprint). Although the DnaA boxes started just upstream to 18-bp iterons, they continued into the iterons resulting to considerable overlap between both the elements. In addition, both the cis-elements contain AT-rich sequences, which are the known signatures of "ori-"like sequences needed for replication initiation in bacteria. In a previous study, three pars-like regions with consensus of GTTTC(A)G(A)C(A)GT(C) $\mathrm{GG}(\mathrm{T}) \mathrm{A}(\mathrm{G}) \mathrm{AAC}$ were mapped at $3.5^{\circ}$ (segS1), $72.9^{\circ}$ (segS2) and $231.8^{\circ}$ (segS3) in chrl (Charaka \& Misra, 2012). The predicted parS-like sequences in chrll and MP are found to be distinct from the conserved segs sequence of chrl. Thus, we found that cisll and cisMP elements have DnaA boxes similar to "oric" feature and the iterons as parS-like sequences. The presence of the different "ori" and pars-like signatures in chrl from that of secondary genome replicons like chrll and MP indicated a strong possibility of independent maintenance of primary chromosome and secondary genome replicons in $D$. radiodurans.

\section{cisll and cisMP elements help E. coli plasmid maintenance in D. radiodurans}

The function of cisll and cisMP as origin of replication was investigated using an E. coli plasmid pNOKOUT $\left(K^{R}{ }^{R}\right)$ that was nonreplicative in $D$. radiodurans. The pNOKCisll and pNOKCisMP mini replicons that contain cis/l and cisMP elements, respectively, were created in PNOKOUT and their independent maintenance in $D$. radiodurans was monitored. The $D$. radiodurans cells harboring pNOKCisll or pNOKCisMP could multiply in the presence of kanamycin $(6 \mu \mathrm{g} / \mathrm{ml})$, which was not observed when these cells were transformed with pNOKOUT vector (Fig 2A and B). Furthermore, the independent maintenance of pNOKCisll or pNOKCisMP mini replicons was also ascertained in $\triangle$ recA mutant of $D$. radiodurans and by recovering the intact plasmid DNA from the recombinant cells. We observed that the $\triangle$ recA cells harboring pNOKCisll or pNOKCisMP replicons continued expressing kanamycin resistance like wild-type transformants of these plasmids (Fig 2C). The plasmids isolated from the wild-type transformants of $D$. radiodurans showed the typical patterns of original plasmid on an agarose gel and the release of the expected size inserts upon restriction digestion (Fig 2D). When we measured the copy number of these plasmids by qPCR, it was found to be $6.86 \pm 0.71$ for pNOKCisll and $12.15 \pm 0.92$ for pNOKCisMP. These results together suggested that pNOKCisll and pNOKCisMP mini replicons have been maintained independently in the $D$. radiodurans cell and not integrated into its genome, supporting the "ori" nature of cisll and cisMP elements in this bacterium. The cis-elements helping the non-replicative 

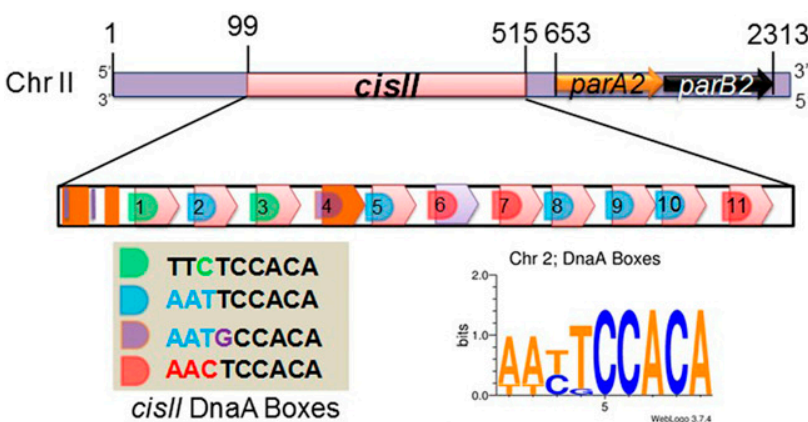

TCCACAAAGTGCCACAGG

CCACAAAGTGCCACAGG

TCCACAAAGTGCCGCAGG

Iterons in cis/l element
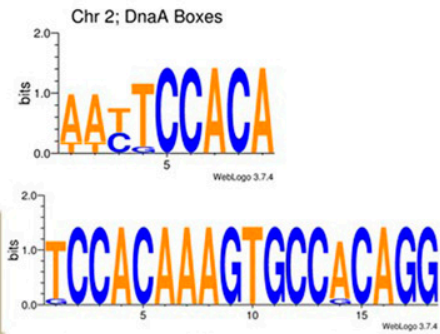

Consensus of Iterons in cisll element

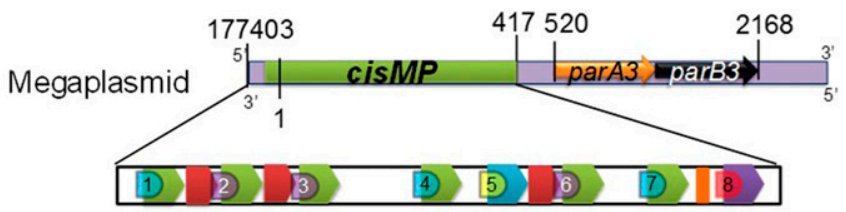

Mp; DnaA Boxes

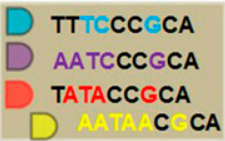

cisMP DnaA Boxes

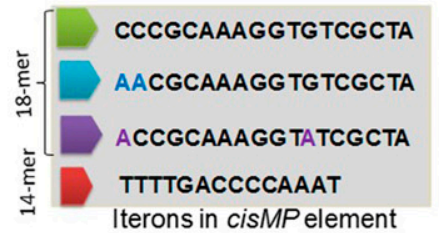

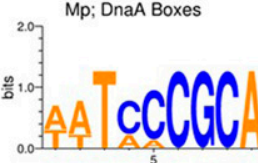

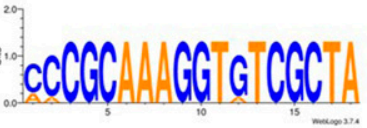

Consensus Iterons in cisMP element

\section{A}

Figure 1. Schematic presentation of direct repeats located upstream to parAB operon in chromosome II (cisII) and megaplasmid (cisMP).

(A, B) The 99-554 bp region of chromosome II (A) and 177,446- to 417-bp region of megaplasmid (B) were analysed in silico for the structure of direct repeats and their sequence compositions of DnaA boxes and iterons.

pNOKOUT plasmid to replicate in $D$. radiodurans, the possibility of these cis-elements working as pars-like sequences and thereby helping in the segregation of these mini replicons into daughter cells was hypothesized.

\section{cisll and cisMP elements provide sequence-specific interaction to} DnaA

The presence of the known DNA replication initiation proteins such as DnaA; RctB of V. cholerae (Egan \& Waldor, 2003); RepC homologues as known in Agrobacterium tumefaciens (Pinto et al, 2011), Brucella abortus (Pinto et al, 2012), Burkholderia pseudomallei (Holden et al, 2004), and S. meliloti (Cervantes-Rivera et al, 2011;
Pinto et al, 2012); and RepN of B. subtilis (Tanaka et al, 2005) and S. aureus (Balson \& Shaw, 1990) were searched on chrl, chrll, and MP of $D$. radiodurans. Chrll and MP do not encode for any of the known DNA replication initiators and DnaA homologue is encoded on chrl (data not given). Thus, the possibility of this DnaA interaction with cis-element of chrll and MP was checked. The recombinant purified DnaA (Fig S1A) showed sequence-specific interaction with both cis/l (Fig 3A) and cisMP (Fig 3B) albeit with a different affinity. The affinity of DnaA varies as the number of repeats was reduced (Fig $3 \mathrm{~A}-\mathrm{H}$ and Table 1). As expected, the DnaA bound to either of the cis-elements remained unaffected even in the presence of an 80-fold higher molar concentration of nonspecific DNA (Fig 3). The formation of DnaA complex with cis/l and cisMP containing several DnaA

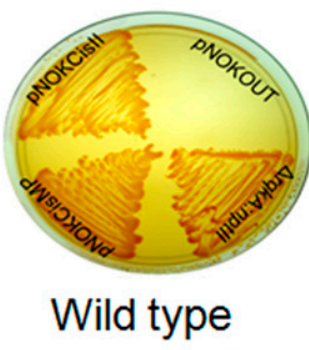

A

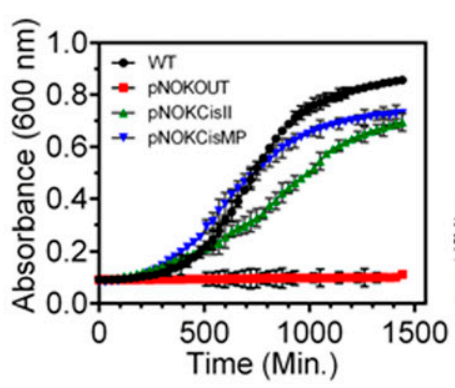

B

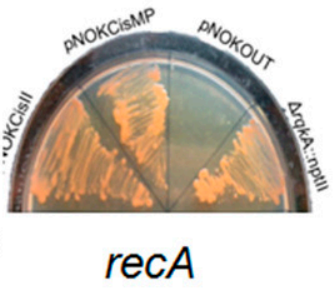

$\mathrm{C}$

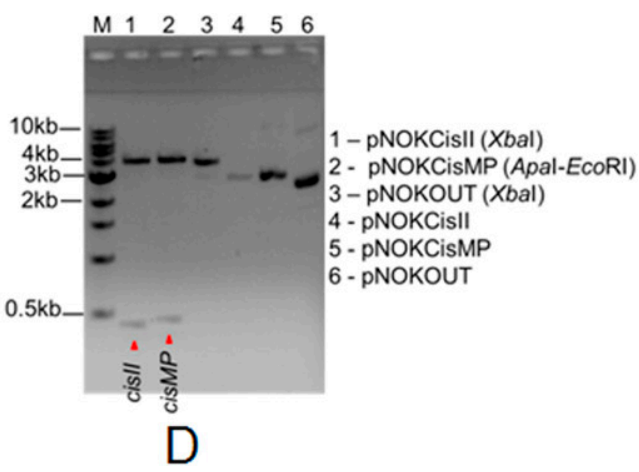

Figure 2. Role of cisll and cisMP elements in the replication of Escherichia coli plasmid into Deinococcus radiodurans.

(A, C) The cisll and cisMP elements were cloned in E. coli cloning vector pNOKOUT, and the resultant plasmids pNOKcisll and pNOKcisMP were transformed into wildtype (A) and recA mutant (C). These transformants were grown in the presence of kanamycin $(6 \mu \mathrm{g} / \mathrm{ml})$ and growth was monitored on TGY agar plate with rqkA deletion mutant (a deletion mutant made by inserting kanamycin cassettes) as described in Rajpurohit \& Misra (2010) as positive control and vector as a negative control. (B) The growth characteristic of these transformants grown in TGY broth supplemented with antibiotic was compared with wild-type cells grown in TGY broth without antibiotics (B). (D) The recombinant plasmids isolated from D. radiodurans cells growing in the presence of antibiotic were digested with restriction enzymes, and the release of cisll and cisMP fragments was analysed on an agarose gel and compared with empty vector (D). 


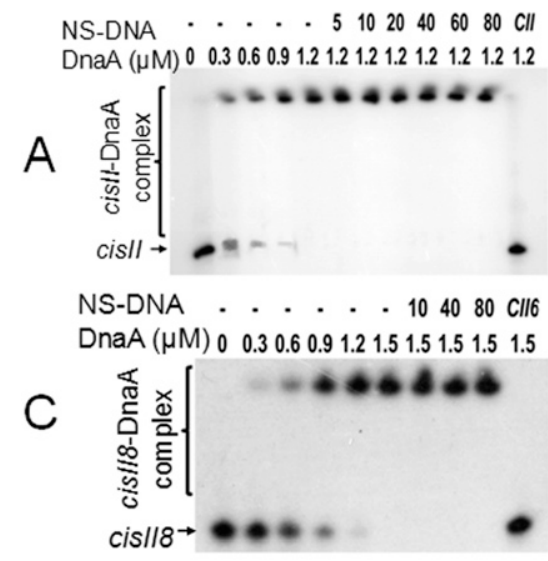

NS-DNA . . . . . $104080 \mathrm{Cll3}$ $\operatorname{DnaA}(\mu \mathrm{M}) 00.30 .60 .91 .21 .51 .51 .51 .51 .5$

E

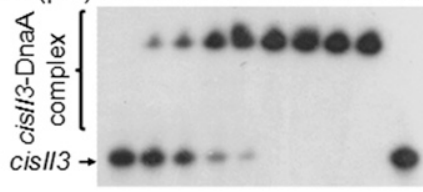

G
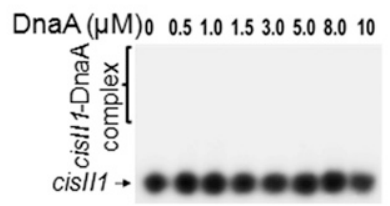

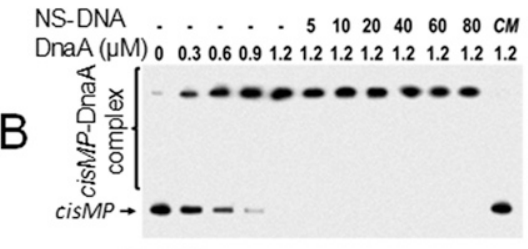

NS-DNA . . . . $104080 \mathrm{cM}$ $\operatorname{DnaA}(\mu M) 0 \quad 0.30 .60 .91 .21 .51 .51 .51 .51 .5$

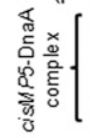

D
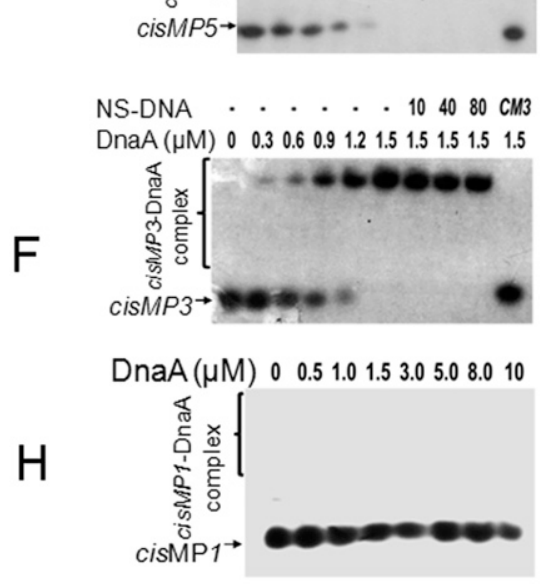

Figure 3. DnaA interaction with cisll and cisMP and their repeats variants.

(A, B, C, D, E, F, G, H) The radiolabelled full-length cisll containing 11 repeats $(A)$ and cisMP containing eight repeats (B) as well as eight repeats (C), three repeats

(E) and one repeat (G) of cisll (Fig S4A), and five repeats (D), three repeats (F), and single repeat (H) of cisMP (Fig S4B) were incubated with the increasing concentration of DnaA. A saturating concentration of the DnaA-DNA ratio was chased with increasing molar ratio of non-specific DNA (NS-DNA) and products were analysed on native PAGE. The fractions of DNA bound with proteins were quantified densitometrically and plotted as a function of protein concentration using GraphPad Prism 6. The Kd for the curve fitting of individual plots was determined and given in Table 1. boxes suggests the "ori" nature of both the cis-elements in $D$. radiodurans.

\section{ParB2 and ParB3 show specific interaction with cognate cis-elements}

Because both the cis-elements have iterons as a potential pars-like sequences and ParB homologues are known to bind pars-like sequences, the interactions of ParB2 and ParB3 with their cognate cis-elements were monitored. The radiolabelled cisll and their repeat variants (Fig 4A-D) as well as CisMP and their repeat variants (Fig 4E-H) were incubated with purified recombinant ParB2 (Fig S1B) and ParB3 proteins (Fig S1C), respectively, and the products were analysed on native PAGE. The ParB2 and ParB3 showed higher affinity with full-length cis/l $(\mathrm{Kd}=0.40 \pm 0.007 \mu \mathrm{M})$ and $\operatorname{cisMP}(0.59 \pm$

Table 1. The dissociation constant (Kd) value of DnaA interaction with different repeats of cisll and cisMP elements.

\begin{tabular}{l|ll}
\multirow{2}{*}{ Repeat no. } & \multicolumn{2}{|l}{ Dissociation constants $(\mathrm{Kd})($ mean $\pm \mathrm{SD}, \boldsymbol{\mu M})$} \\
\cline { 2 - 3 } & cisll variants & cisMP variants \\
\hline Full length & $0.31 \pm 0.004$ & $0.56 \pm 0.21$ \\
\hline $8 / 5$ repeats & $0.70 \pm 0.35$ & $0.89 \pm 0.39$ \\
\hline 3 repeats & $0.80 \pm 0.11$ & $1.4 \pm 0.7$ \\
\hline 2 repeats & Poor affinity & Poor affinity \\
\hline 1 repeat & No affinity & No affinity \\
\hline
\end{tabular}

$0.05 \mu \mathrm{M}$ ), respectively (Fig $4 \mathrm{~A}$ and $\mathrm{E}$ ). The affinity of ParBs to cognate cis-element was nearly same up to three repeats and reduced when the number of repeats becomes less than three (Fig $4 \mathrm{C}$ and $\mathrm{G}$ and Table 2). These proteins are sparingly bound to DNA substrates with less than two repeats (Fig 4D and H). The binding of ParBs to the cognate cis-elements was sequence specific as it was not affected in the presence of up to 100-fold higher molar concentration of nonspecific DNA (Fig $4 \mathrm{~A}-\mathrm{C}$ and $\mathrm{E}-\mathrm{G}$ ). Furthermore, it was noticed that the full-length cisll and cisMP bound ParBs migrated under electrophoresis with peculiar patterns that are normally seen when the protein binding causes a structural change like bending in the DNA. These findings suggested that both cisll and cisMP elements have a specific region for interaction with respective ParB2 and ParB3, which might function as pars-like sequence in the faithful segregation of cognate replicons.

\section{cisll and cisMP deletion affected cognate replicons copy number} and their segregation

To understand the essentiality of chrl, chrll, and MP, the possibility of deleting cisll, cisMP, and putative ori of chrl (oriCl) was explored. We could not obtain the deletion mutant of oriCl. However, the homozygous replacement of cisll (Fig S2A and B) and cisMP (Fig S2A and $C$ ) with an expressing cassette of $n p t / l$ was achieved, and these cells were viable in both liquid medium and agar plates. Therefore, the effects of cisll and cisMP deletion on the stability of cognate replicons and their genome copy numbers were determined in mutant cells and compared with wild type. A significant reduction in 


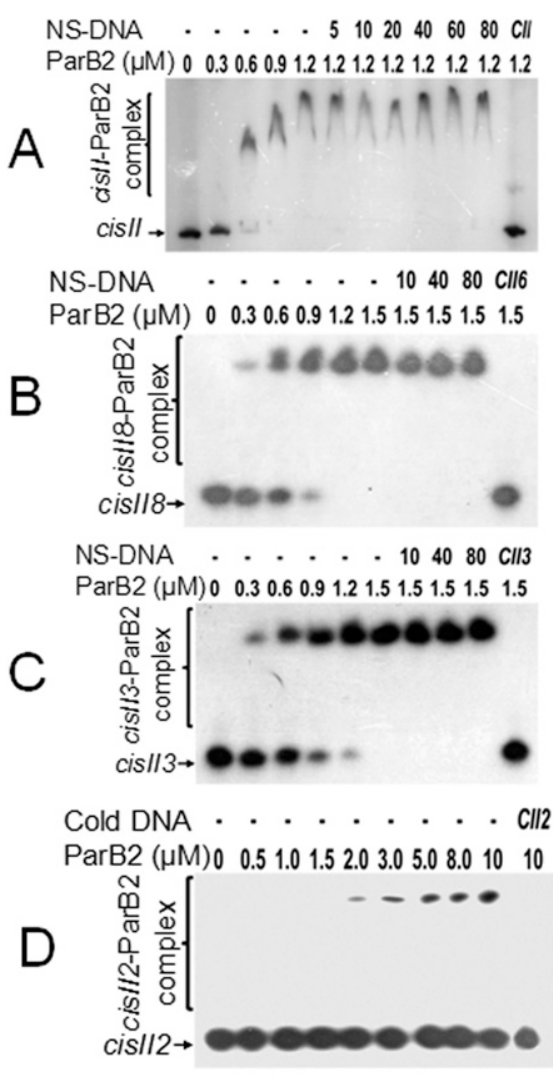

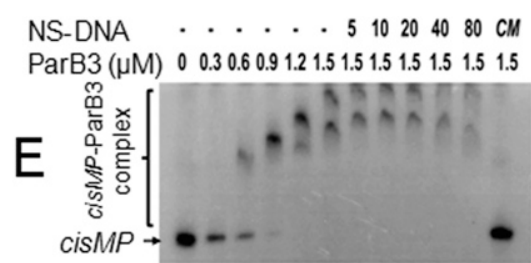

NS-DNA . . . . . $104080 \mathrm{CM5}$ $\operatorname{ParB}(\mu \mathrm{M}) 00.30 .60 .91 .21 .51 .51 .51 .51 .5$

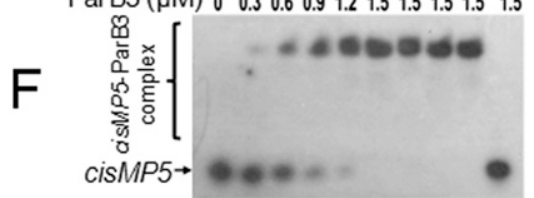

NS-DNA . . . . . $104080 \mathrm{CM3}$ ParB3 $(\mu \mathrm{M}) 0 \quad 0.30 .60 .91 .21 .51 .51 .51 .51 .5$
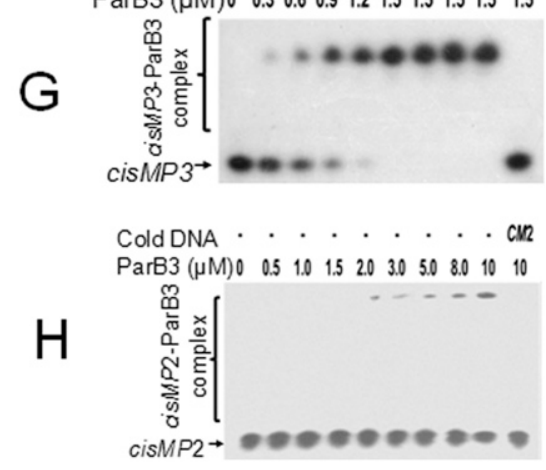

Figure 4. ParBs interaction with cisll and cisMP and their repeats variants.

(A, B, C, D) The radiolabelled full-length cis/l containing 11 repeats $(A), 8$ repeats $(B), 3$ repeats $(C)$, and 2 repeats (D) (Table S2) were incubated with the increasing concentration of ParB2. (E, F, G, H) Similarly, the radiolabelled full-length cis $M P$ containing eight repeats $(E)$, five repeats $(F)$, three repeats $(G)$, and two repeats $(\mathrm{H})$ were incubated with the increasing concentration of ParB3. A saturating concentration of DNA-protein ratio was chased with increasing molar ratio of non-specific DNA (NS-DNA) and products were analysed on native PAGE. The fractions of DNA bound with proteins were quantified densitometrically and plotted as a function of protein concentration using GraphPad Prism 6. The Kd for the curve fitting of individual plots was determined and given in Table 2. the copy number of chrll and MP was observed in $\triangle$ cisll and $\triangle$ cisMP cells, respectively, but the copy number of chrl did not change in any of the mutant backgrounds (Fig 5A). For instance, the average copy number of chrll reduced from $5.95 \pm 0.32$ to $1.55 \pm 0.22$ and MP was reduced from $10.85 \pm 0.24$ to $8.52 \pm 0.81$ in $\Delta$ cis/l mutant. Similarly, the average copy number of MP was reduced from $10.85 \pm$ 0.24 to $2.42 \pm 0.35$ in $\triangle$ cisMP mutant (Fig 5A). The deletion of cisMP did not affect the copy number of either chrl or chrll when compared with wild type. The reduction in ploidy of secondary genome replicons in deletion mutant of cognate cis-elements could be accounted for its effect on the replication of these replicons. However, a possibility of these deletions affecting DNA segregation in dividing cells cannot be ruled out. This possibility was checked by monitoring the frequency of cells conferring $\mathrm{Kan}^{\mathrm{R}}$ (expressed on Chrll or MP) when grown in the absence and presence of kanamycin. In general, the growth of cis mutants was affected as compared with wild type and reduced further when grew in the presence of kanamycin as compared with its absence (Fig 5B). Furthermore, the $\triangle$ cisll and $\triangle$ cisMP mutants were grown for $14 \mathrm{~h}$ (log phase) in the presence and absence of kanamycin and total CFUs were measured in TGY agar plate in the presence and absence of antibiotic. Results showed that $\mathrm{Kan}^{\mathrm{R}} \mathrm{CFU}$ was reduced nearly half (-Kan vs +Kan) in both the mutants when they were grown without selection pressure, whereas there was no change in $\mathrm{Kan}^{\mathrm{R}}$ CFU (-Kan vs +Kan) when these mutants were maintained with antibiotic selection (Fig 5C). Because the antibiotic is expressed on respective replicons, these results indicated that all daughter cells grown without selection pressure might have not inherited cognate replicon in cis mutant. Therefore, a possibility of chrl alone supporting the normal growth of this bacterium was suggested.

Table 2. The dissociation constant (Kd) value of ParB2 and ParB3 interaction with repeats variants of cisll and cisMP elements, respectively.

\begin{tabular}{l|lr}
\multirow{2}{*}{ No. of repeats } & Dissociation constants $(\mathbf{K d})($ mean \pm SD, $\boldsymbol{\mu M})$ & ParB3 with cisMP variants \\
\cline { 2 - 3 } & ParB2 with cisll variants & $0.59 \pm 0.06$ \\
\hline Full length & $0.40 \pm 0.006$ & $0.81 \pm 0.04$ \\
\hline $8 / 5$ repeats & $0.68 \pm 0.06$ & $1.01 \pm 0.15$ \\
\hline 3 repeats & $1.06 \pm 0.26$ & Poor affinity \\
\hline 1 repeats & Poor affinity & Poor affinity \\
\hline
\end{tabular}



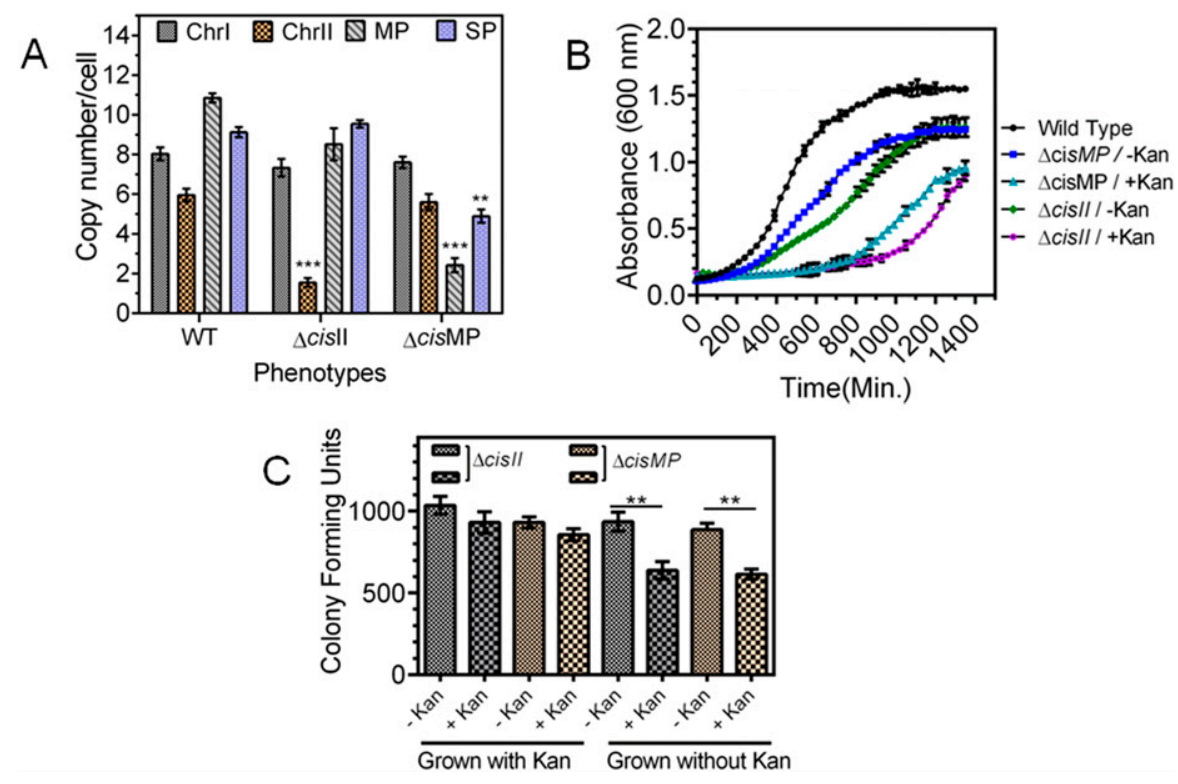

Figure 5. Effect of cisll and cisMP deletions on genome copy number and radioresistance in $D$. radiodurans.

(A) The exponentially growing $D$. radiodurans R1 (WT) and its cisll $(\triangle \operatorname{cis} / l)$ and $\operatorname{cisMP}(\triangle \operatorname{cis} M P)$ deletion mutants were used for the determination of copy number of each replicon (A). (B) Both wild type and cis mutants of $D$. radiodurans were checked for growth in the presence and absence of kanamycin under normal conditions (B). (C) These mutants were maintained in the presence (+Kan) and absence (-Kan) of antibiotics as indicated on $x$-axis, and the CFUs in the absence and presence of kanamycin were monitored and plotted on y-axis (C)
Similar studies have been reported in B. subtilis and Mycobacterium tuberculosis (Hassan et al, 1997; Qin et al, 1999; Richardson et al, 2016, 2019). These results together suggested that cisll and cisMP elements seem to carry functions for controlling both DNA replication and segregation in D. radiodurans. Furthermore, the status of chrll and MP in cis mutants was examined microscopically. cisll and cisMP deletions affected the maintenance of cognate genomic replicons

The multipartite genome system, ploidy, and packaging of complete genetic materials into a doughnut-shaped toroidal nucleoid are considered to be the remarkable cytogenetic features in $D$. radiodurans (Harsojo \& Matsuyama, 1981; Levin-Zaidman et al, 2003;
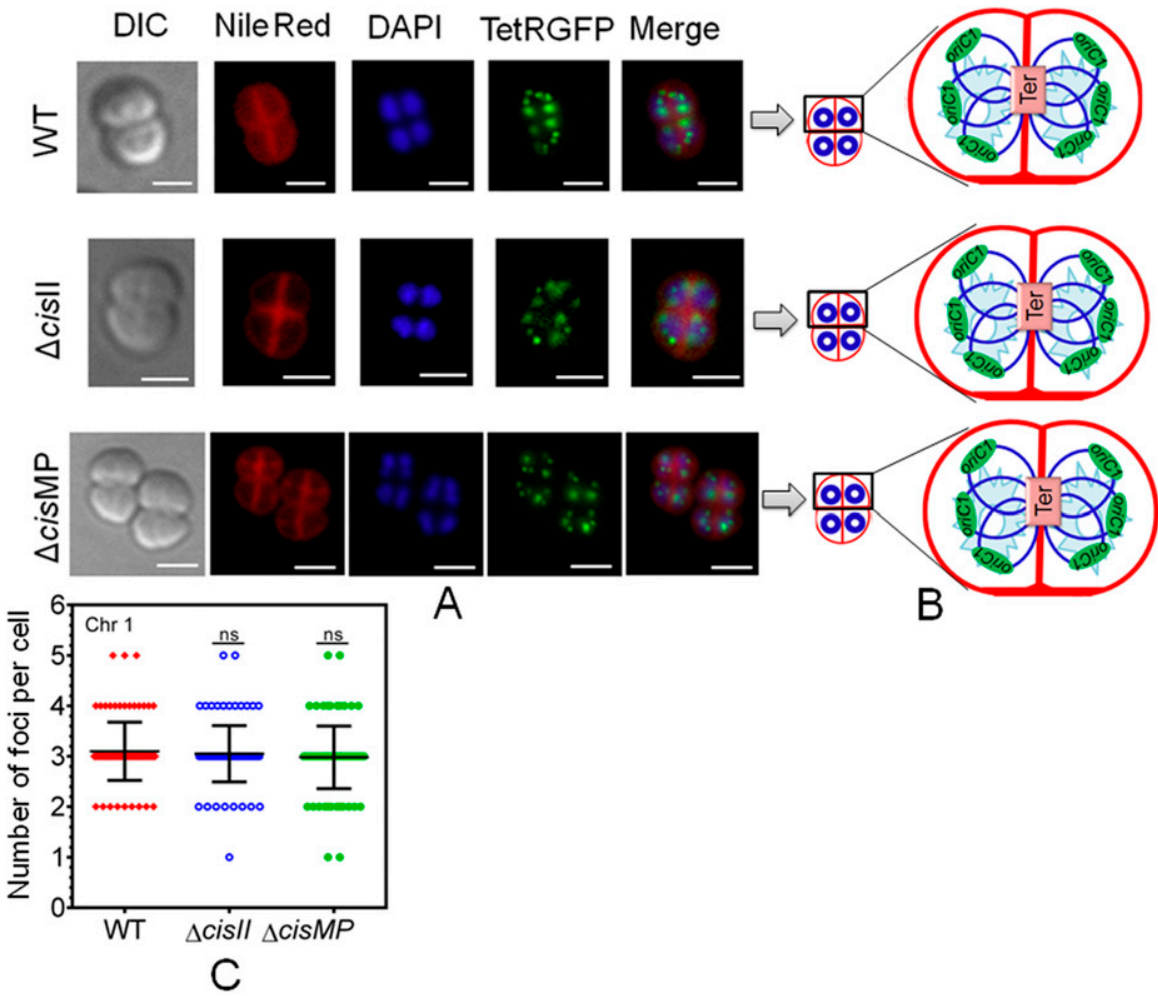
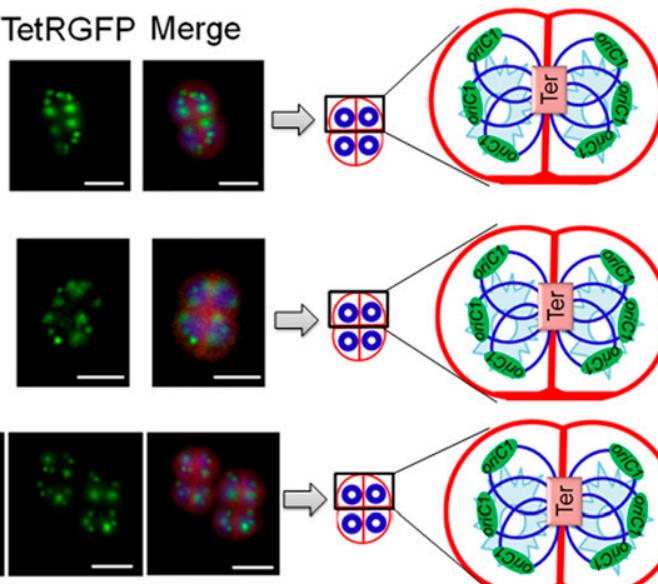

A
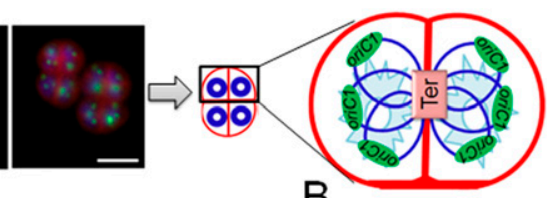

B
Figure 6. The localization pattern of chromosome I in the nucleoid of wild type and secondary genome cis mutants of Deinococcus radiodurans.

Chromosome I was tagged with teto/TetR-GFP-based fluorescent reporter-operator system in both wild type (WT) and cis mutants ( $\triangle c i s / l$ and $\triangle$ cisMP) as described in the Materials and Methods section and grown exponentially. (A) These cells were stained with Nile Red and DAPI and visualized microscopically in differential interference contrast, TRITC (Nile Red), DAPI (DAPI), and FITC (GFP) channels and images were merged (Merge) (A). The scale bar of $1 \mu \mathrm{m}$ is used in each figure. (B) The schematic diagrams showing the foci position with respect to nucleoid and septum are presented for better clarity (B). (C) Data shown are from a single tetrad where most of these cells show a similar pattern as quantified from $\sim 200$ cells (C). 

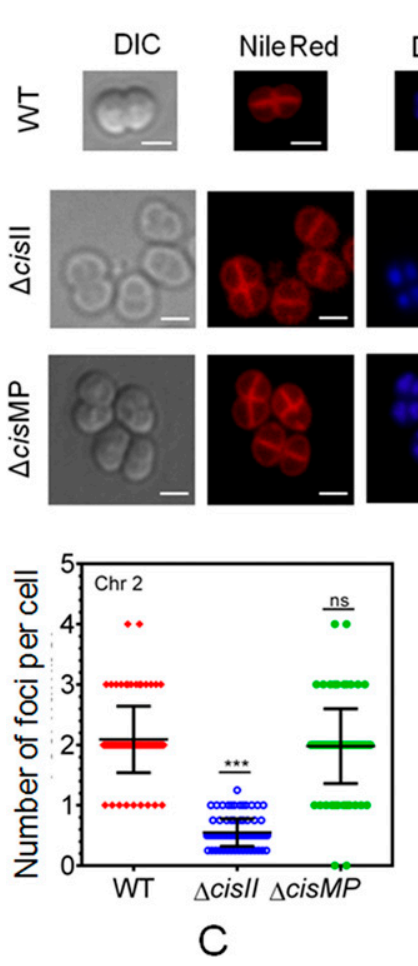

Minsky et al, 2006). However, the organization of genomic replicons in toroidal nucleoid has not been demonstrated. In this work, we developed an FROS approach for the chrl (Fig S3A), chrll (Fig S3B), and MP (Fig S3D) in the wild-type, and $\Delta$ cisll- and $\Delta$ cisMP-mutant cells as described in the Materials and Methods section (Fig S3C and E). The exponentially growing cells were stained with Nile red and DAPI and imaged under a fluorescence microscope. Interestingly, the localization pattern of chrl in the $\triangle$ cisll and $\triangle$ cisMP mutants and wild-type cells were similar (Fig 6A). The average number of foci for chrl per cell was $\sim 3$, which were localized away from the septum and seems to be radially distributed throughout the cytoplasm in both wild type and $\triangle$ cisll and $\triangle$ cisMP cells (Fig $6 \mathrm{~B}$ and C). A nearly similar pattern of chrl localization has been recently demonstrated in $D$. radiodurans, where the number of foci per nucleoid was shown to be in the range of 2.25-4.44 (Floc'h et al, 2019). However, when the localization pattern of chrll (Fig 7A) and MP (Fig 8A) was observed under microscope, the average number of foci for chrll (Fig 7A-C) and MP (Fig 8A-C) was found to be 2.09 and 1.1 per cell, respectively. These were too located away from the septum and spanned throughout the nucleoid in wild type. However, in the case of cis mutant, the localization pattern of chrll and MP was different. For instance, chrll localization in nucleoid was altered in $\Delta c i s / l$ but not in $\triangle$ cisMP and vice versa. Both these cis mutants produced a population of cells that did not contain the cognate replicon. Because the qPCR study has shown the highest number (10.85) of copies of megaplasmid per cell, the single GFP foci observed through FROS is intriguing but informative. Similar results have been reported in other limited copy plasmids such as RK2, R1, etc. in E. coli (Weitao et al, 2000; Pogliano et al, 2001). The decreasing number of GFP foci from 3 to 4 in Chrl to one in MP agreed with their size difference and if that has affected resolution cannot be ruled out.

Furthermore, we studied the population dynamics of cells for the presence and absence of chrl, chrll and MP in wild type and cis mutants. The majority of wild type cells showed $\geq 3$ foci corresponding to chrl, 2 foci for chrll and single focus for MP (Fig 9A). However, the number of cells with $\geq 3$ foci corresponding to chrl in both the cis mutants was nearly similar to wild type. For chrll, these were nearly the same in cisMP mutant and wild type with two foci in each. However, in cis/l mutant, there was hardly any cell containing two foci and all the population was divided almost equally into cells with a single focus or no focus (Fig 9B). Similarly, wild-type and cis/l mutant showed a nearly similar number of foci corresponding to $M P$, which was different in cisMP mutant. For instance, the cisMP mutant showed nearly half of the cells with a single focus and the other half population did not show foci corresponding to MP (Fig 9C). These results highlighted the roles of cisll and cisMP as "ori" and pars-like functions in the secondary genome replicons of $D$. radiodurans. Furthermore, the FROS-based localization provided the first evidence that both primary and secondary genome replicons are the part of the compact nucleoid and these replicons seem to be independently maintained in this multipartite genome-harboring bacterium.

\section{cisll and cisMP mutants showed reduction in $\gamma$-radiation resistance}

The effect of cisll and cisMP deletion on $y$ radiation response of $D$. radiodurans was examined. The $\Delta$ cis/l mutant was more sensitive to $\gamma$ radiation than $\triangle$ cisMP mutant (Fig 10). Furthermore, the mutants 

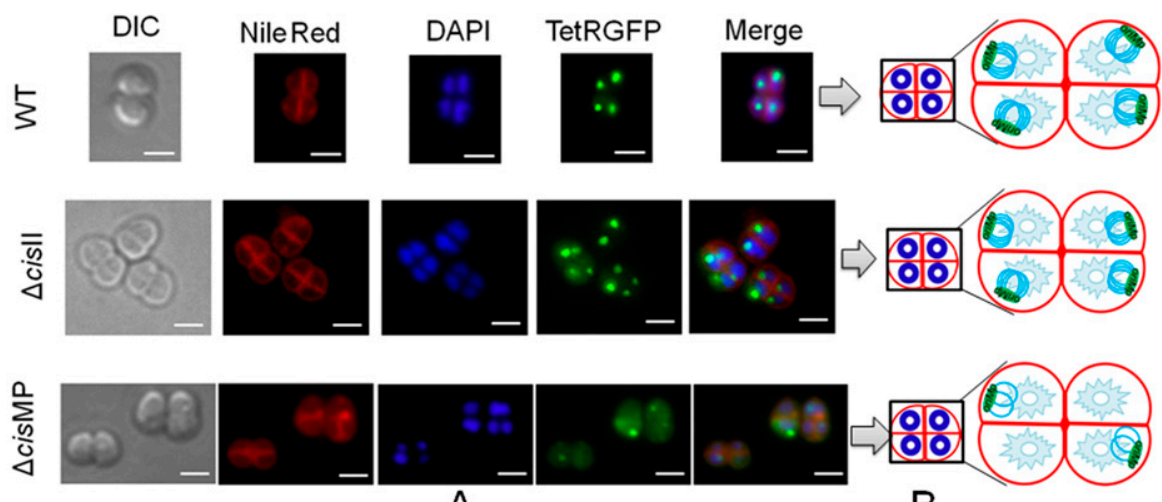

A

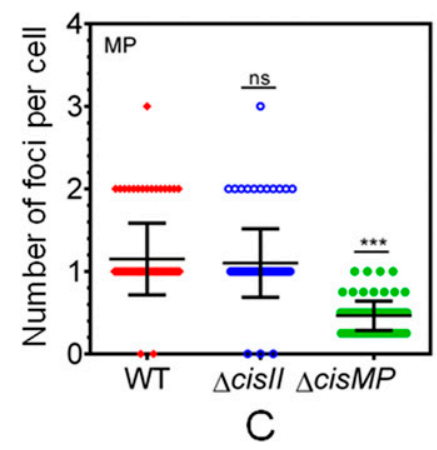

that were maintained without antibiotic selection showed nearly twofold higher sensitivity to $y$ radiation as compared with those grown with antibiotic (Fig 10). The loss of $y$ radiation resistance in cis mutants that apparently had shown the reduction in copy number in nearly half of the population, and the other half were anucleated for cognate replicons, suggested the role of chrll and MP in radioresistance of this bacterium. Earlier, it was shown that the reduction in copy number of chrll and MP in $\triangle$ parA2 $\triangle$ parA3 double mutants has affected $\gamma$ radiation response in $D$. radiodurans (Maurya et al, 2019a). The mechanisms responsible for the underlying loss of radioresistance in cells that have either a reduced copy number or the complete loss of chrll and MP are not understood. However, these replicons encode a large number of proteins including PprA (Narumi et al, 2004), DR_A0282 (Das \& Misra, 2011), DR_A0074, and DR_A0065 (Ghosh \& Grove, 2006) on chrll, and DR_B0100 (Kota et al, 2010), DR_B0090, and DR_B0091 (Desai et al, 2011), which have been characterized for their roles in DNA repair and radioresistance (Misra et al, 2013). Therefore, the reduction in the copy number or the absence of these proteins in cis mutants if have affected the radioresistance of $D$. radiodurans cannot be ruled out. These results suggested that chrll and MP replicons, which are perturbed in cisll and cisMP mutants, contributes to the radioresistance in this bacterium.

\section{Discussion}

D. radiodurans, an extraordinary radioresistant bacterium is characterized for its peculiar cytogenetic features like the multipartite
Figure 8. The localization pattern of megaplasmid in the nucleoid of wild type and secondary genome cis mutants of Deinococcus radiodurans.

The megaplasmid was tagged with a tetO-TetRGFP-based fluorescent reporter-operator system in both wild type (WT) and cis mutants ( $\triangle$ cis/l and $\triangle c i s M P$ ) as described in the Materials and Methods section and grown exponentially. (A) These cells were stained with Nile Red and DAPI and visualized microscopically in differential interference contrast, TRITC (Nile Red), DAPI (DAPI), and FITC (GFP) channels and images were merged (Merge) (A). The scale bar of $1 \mu \mathrm{m}$ is used in each figure. (B) The schematic diagrams showing the foci position with respect to nucleoid and septum are presented for better clarity (B). (C) Data shown are from a single tetrad where most of these cells show a similar pattern as quantified from $\sim 200$ cells (C). genome, ploidy, and tetrad cell morphology. Mechanisms underlying DNA replication and genome segregation have not been studied in detail in this bacterium, and very limited information is available in other MGH bacteria such as V. cholerae, R. sphaeroides, S. meliloti, and D. radiodurans (Fogel \& Waldor, 2005; Charaka \& Misra, 2012; Dubarry et al, 2019; Maurya et al, 2019a). Recently, the nucleoid dynamics and radial positioning of ori and ter in chrl of $D$. radiodurans have been demonstrated as a function of cell cycle (Floc'h et al, 2019). However, the organization of the secondary genome replicons in the nucleoid and their stable inheritance in dividing cells under normal and $y$ radiation stressed conditions had not been studied. This study has brought forth some evidences to suggest that the direct repeats present upstream to parAB operon in chrll (cisll) and MP (cisMP) function like "ori" and pars-like elements in D. radiodurans. By using FROS approach, we demonstrated the radial localization of chrl, chrll, and MP in the nucleoid and away from septum. The search of the homologues of RepC encoded on secondary genome element in $A$. Tumefaciens, B. abortus, B. pseudomallei, and S. Meliloti and RctB in $V$. cholerae did not pick up these proteins in the chrll and MP in D. radiodurans (data not shown). However, chrl encodes the DnaA homologue of E. coli. This does not rule out the possibility of some uncharacterized replication initiators for secondary genome elements in this bacterium.

We used DnaA and ParBs as probes for ori and pars-like sequences and confirmed that cisll and cisMP elements have both DnaA boxes and iterons. Our results demonstrating the (i) conversion of a non-replicative plasmid into a replicative one in the presence of these cis-elements, (ii) reduction in copy number of cognate replicon in absence of these elements, and (iii) an increased frequency of cells devoid of chrll and MP in respective 

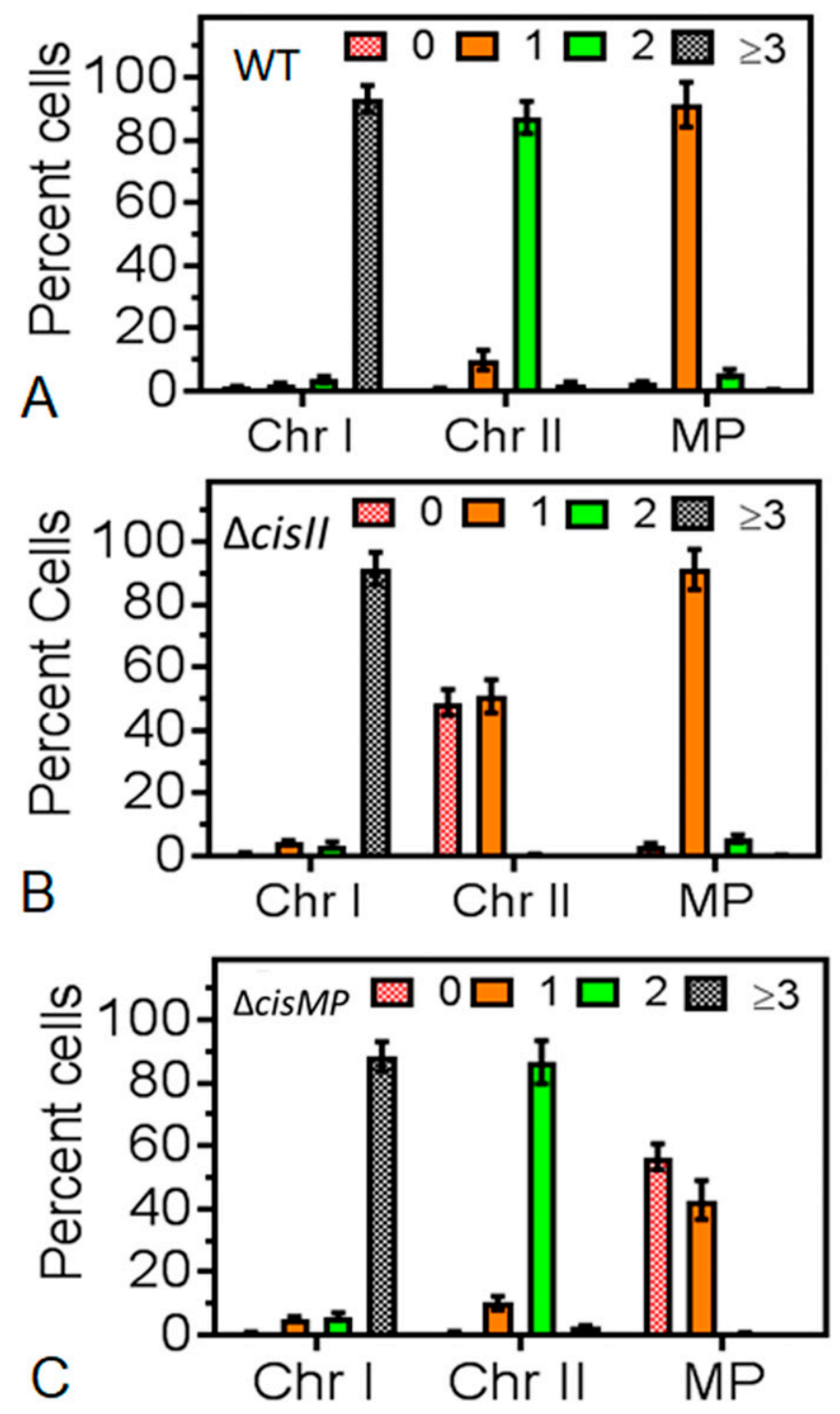

Figure 9. Distribution of genomic replicons in wild type and cis mutants of Deinococcus radiodurans observed under fluorescence microscopy.

(A, B, C) The chromosome I (Chrl), chromosome II (Chrll and megaplasmid [MP]) of wild type (A), cisll (B), and cisMP (C) mutant of $D$. radiodurans were tagged with GFP-based fluorescent reporter-operator system and cells were imaged under fluorescence microscopy as described in Figs 6-8. Nearly 200 cells of each type were analysed for the absence $(0)$ and the presence of varying numbers $(1,2, \geq 3)$ of foci corresponding to all three replicons. Data presented here are mean \pm SD $(n=200)$.

deletion mutant, together supported the hypothesis that both cis/l and cisMP elements play the important roles in the regulation of DNA replication and segregation functions in this bacterium. The presence of both "ori" and pars-like sequences in close vicinity, if helps the cells to differentially regulate the growth phase dependent interaction of replication complex with ori region and segregation complex with pars-like region cannot be ruled out. Earlier, the presence of pars-like sequences in proximity to "oriC" in their chromosomes and the molecular crosstalk between the components of the macromolecular events like replication and segregation has also been reported in some bacteria. For instance, in B. subtilis, Soj (a ParA homologue) directly interacts with DnaA proteins and regulates the replication at oric (Scholefield et al, 2011). In C. crescentus, DnaA controls chromosome segregation in ParA dependent manner as well as by binding directly to the pars site (Marczynski et al, 2019). Although both the chromosomes in $\mathrm{V}$. cholerae encode separate replication and segregation components (Egan \& Waldor, 2003), the interdependent regulation of these two processes has been observed. For instance, ParA1, a genome segregation protein, encoded on chrl in V. cholerae stimulates DNA replication through its direct interaction with DnaA while ParB2, a pars binding protein, encoded on chrll showed inhibition of replication initiation in chrl (Kadoya et al, 2011). On contrary, ParB2 stimulates the replication of chrll by decreasing RctB binding to inhibitory DNA sequences adjacent to the orill in V. cholerae (Pal et al, 2005; Venkova-Canova et al, 2013). In D. radiodurans, the interaction of segregation proteins with replication initiation proteins (DnaA and DnaB) and an arrest of genome segregation affecting DNA replication have been demonstrated (Maurya et al, 2019b; Maurya \& Misra, 2020 Preprint). Although secondary genome elements in D. radiodurans do not encode for any of the known DNA replication initiation proteins, and cisll and cisMP are being implied to regulate DNA replication through DnaA, the possibility of some additional uncharacterized mechanism(s) for the regulation of replication in chrll and MP cannot be ruled out.

Furthermore, we tried to distinguish the replication and segregation functions of these cis-elements in vivo. We could delete cisll and cisMP from cognate genome elements but not oriCl from chrl of this bacterium and these cells were viable under normal conditions indicating a strong possibility that chrll and MP replicons are not required for the normal growth in this bacterium. Microscopically, we observed that only nearly half of the populations of $\triangle c i s / l$ and $\triangle c i s M P$ mutants lack cognate replicon indicating a possibility of functional redundancy of these cis-elements in regulation of DNA replication in chrll and MP. Because chrll was designated as chromosome because of the presence of certain essential genes as chromosomal markers, nearly no effect of cis/l deletion on survival of $D$. radiodurans is intriguing. However, the growth rates of these mutants under normal conditions and in the absence of antibiotic selection were different from the wild type. Results supported the hypothesis where we observed (i) the reduction in copy number of cognate replicons in mutant grown under antibiotic selection and (ii) the sizable cell populations of mutants did not have cognate replicons as monitored by the absence of antibiotic resistance encoded on them as well as microscopically. We argued that cis mutants, which were maintained without antibiotic selection may have grown as the heterogeneous population having cells with and without cognate replicons. When these are selected for $\mathrm{Kan}^{\mathrm{R}}$, nearly half of the population was found to be $\mathrm{Kan}^{\mathrm{S}}$ (Fig 5B and C). Presumably, these were the ones that have survived with the help of chromosome I and were devoid of secondary replicons because of segregation defects. Although mutational analysis of these repeats and their interaction with cognate ParBs has provided a strong evidence on the role of these elements in genome segregation, loss of chrll and MP in nearly 50\% population of cisll and cisMP mutants, respectively, also supports the role of these cis-elements in genome segregation. 


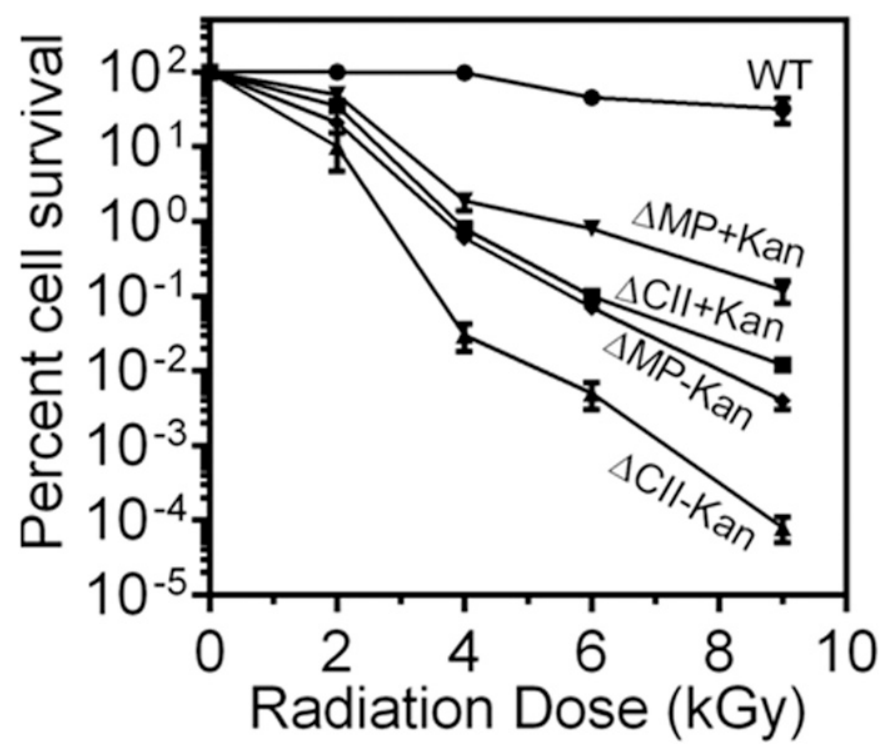

Figure 10. Gamma radiation response of cisll and cisMP mutants of Deinococcus radiodurans.

The $y$ radiation response of wild type (WT) and its cis/l $(\triangle \mathrm{CII})$ and cisMP $(\triangle M P)$ mutants grown in the presence (+Kan) and absence (-Kan) of kanamycin was monitored. Data presented here are mean \pm SD $(n=6)$ from the reproducible experiments.

Furthermore, the FROS results where $2-3$ cells in tetrad were devoid of foci in respective replicons supported the argument of segregation defect in cells lacking cis-elements. Survival of other three cells in tetrad without replicons conferring antibiotic resistance under selection pressure is intriguing and a strong possibility of these supported by the neighbouring antibiotic-resistant cells cannot be ruled out. The careful monitoring of the localization pattern of chrl, chrll, and MP in nucleoid of wild type and cis mutants yielded very interesting results. The localization pattern of chrl was the same in both wild type and cis/l and cisMP mutants, and agrees with the recent findings reported independently (Floc'h et al., 2019). Also, there was no change in the ploidy status of chrl in mutant cells. On the other hand, the localization pattern of chrll and MP in the nucleoid as well as the ploidy status of these replicons in cells deleted for cis/l and cisMP elements, respectively, were grossly altered. Thus, we provided evidence that all three replicons are packaged in a single nucleoid and the "ori" region of these replicons is excluded from the membrane-proximal region of the cell. The anchoring of the chromosome to membrane-proximal region through SMC proteins has been reported in other bacteria (Ben-Yehuda et al, 2005; Thanbichler \& Shapiro, 2006; Yamaichi et al, 2012). It would be worth mentioning that ParAs encoded on Chrll and MP are found to be functionally redundant (Maurya et al, 2019a), while ParB2 and ParB3 are not (Maurya et al, 2019b), and now cis-elements are differentially regulating both replication and segregation of cognate replicons in this bacterium.

In conclusion, for the first time, we have characterized the ori and pars-like regions in cisll and cisMP elements in chrll and MP and showed that these cis-elements regulate replication and segregation functions in an MGH bacterium D. radiodurans. Furthermore, we provided evidence that the maintenance of these secondary replicons is independent of the primary chromosome, yet the chrl, chrll, and MP are packaged in form of a compact nucleoid. Last, this study also provides evidence that the secondary genome replicons have roles in the extraordinary radioresistance of this bacterium. Recently, many bacteria have been discovered with a multipartite genome system, and surprisingly the most of these are pathogenic/ inhabitant to some forms of life. Regulation of origin of replication, incompatibility and copy number as understood by taking E. coli as model system, would be worth revisiting in the context of ploidy and multipartite genome system as known in many MGH bacteria. This study may serve as an example and provide starting materials for answering many of these questions under newly born multipartite genome biology in bacteria. Apart from this, the independent studies would be undertaken to understand (i) the dynamics of the multipartite genome during $y$ radiation recovery and normal cell cycle regulation in this bacterium, and (ii) DNA damage responsive territorial change of genomic replicons in cells recovering from $y$ radiation exposure and its impact on genome functions in $D$. radiodurans. The presence of chrll and MP in certain population of cisll and cisMP mutants, respectively, does not rule out a strong possibility of DnaA and cisll or cisMP independent regulation of replication in these replicons and would be worth investigating independently.

\section{Materials and Methods}

\section{Bacterial strains, plasmids, and materials}

D. radiodurans $\mathrm{R} 1$ (ATCC13939) was grown in TGY (1\% tryptone, 0.1\% glucose, and $0.5 \%$ yeast extract) medium at $32^{\circ} \mathrm{C}$. E. coli strain NovaBlue was used for cloning and maintenance of all the plasmids, whereas E. coli strain BL21 (DE3) pLysS was used for the expression of recombinant proteins. The pNOKOUT plasmid (a nonreplicative plasmid in $D$. radiodurans) was used for generating gene knockouts and bioassay of cis-elements for origin of replication function in D. radiodurans. Standard protocols for all the recombinant techniques were used as described earlier (Green \& Sambrook, 2012). Molecular biology grade chemicals and enzymes were procured from Merck Inc. and New England Biolabs. Radiolabeled nucleotides were purchased from the Board of Radiation and Isotope Technology, Department of Atomic Energy, India (BRIT). All the oligonucleotides used in this study are listed in Table S1 and all bacterial strains and plasmids are listed in Table S2.

\section{Bioinformatic analysis}

The nucleotide sequences close to the origin region and upstream to parAB operons in the circular map of Chrll (99-544 bp region) and MP (177,446-417 bp region) were analysed for potential repeats and consensus sequence using Mellina II web tool (Okumura et al, 2007) and WebLogo online tool (Crooks et al, 2004) and tentatively named as cisll and cisMP, respectively. The putative DnaA boxes in cisll were predicted using DOriC database (DoriC accession numberORI10030006) (Luo \& Gao, 2019). The DnaA boxes in cisMP were 
marked based on sequence homology with known DnaA boxes from other bacteria.

\section{Cloning of cis-elements and their maintenance}

The cisll and cisMP were PCR-amplified from genomic DNA of D. radiodurans using cisIIFw/cisllRw and cisMPFw/cisMPRw primers, respectively (Table S1). The cis/l was cloned at Xbal site, whereas cisMP at Apal and EcoRI sites in pNOKOUT (Khairnar et al, 2008) to yield pNOKcisll and pNOKcisMP plasmids, respectively (Table S2). These plasmids were transformed in both wild type and recA mutant of $D$. radiodurans and transformants were scored at kanamycin $(6 \mu \mathrm{g} / \mathrm{ml})$ containing TGY agar plates. For plasmid maintenance, the transformants were streaked on kanamycin containing TGY agar plates. The bacterial growth was also monitored in TGY liquid medium in the presence of antibiotic as required, at $32{ }^{\circ} \mathrm{C}$ and $\mathrm{OD} 600 \mathrm{~nm}$ was monitored using Synergy $\mathrm{H} 1$ Hybrid Multi-mode microplate reader, Bio-Tek. The maintenance of pNOKcisll and pNOKcisMP plasmids in D. radiodurans was confirmed with antibiotic resistance as well as by isolating these plasmids from transformant as described earlier (Meima \& Lidstrom, 2000). The isolated plasmid DNA was digested with Xbal in the case of pNOKcisll and Apal and EcoRI in the case of pNOKcisMP, and the restriction digestion pattern was compared with the original plasmid on the agarose gel.

\section{Protein purification}

The recombinant DnaA of $D$. radiodurans expressing on $\mathrm{DETDnaA}$ in E. coli BL21 (DE3) pLysS was purified by Ni-NTA affinity chromatography as described earlier (Maurya \& Misra, 2020 Preprint). In brief, E. coli cells carrying pETDnaA were induced with $0.5 \mathrm{mM}$ isopropyl- $\beta$-D-thio-galacto-pyranoside (IPTG) and cell pellet was suspended in buffer A (20 mM Tris- $\mathrm{HCl}, \mathrm{pH} 7.6,300 \mathrm{mM} \mathrm{NaCl}$ and $10 \%$ glycerol), $0.5 \mathrm{mg} / \mathrm{ml}$ lysozyme, $1 \mathrm{mM}$ PMSF, $1 \mathrm{mM} \mathrm{MgCl} 2,0.05 \% \mathrm{NP}-40$, $0.05 \%$ Triton $\mathrm{X}-100$, and protease inhibitor cocktail. The resultant mixture was sonicated on ice and cell lysate was centrifuged at $13,500 \mathrm{~g}$ for $30 \mathrm{~min}$ at $4^{\circ} \mathrm{C}$ and the clear supernatant was purified through Ni-NTA column chromatography (GE Healthcare). The recombinant ParBs encoded on chromosome II (ParB2) and megaplasmid (ParB3) in D. radiodurans were purified from recombinant E. coli using Ni-NTA affinity chromatography (Maurya et al, 2019b). Fractions with $>95 \%$ purity were pooled and purified from HiTrap Heparin HP affinity columns (GE Healthcare Life Sciences) using a linear gradient of $20-300 \mathrm{mM} \mathrm{NaCl}$, followed by precipitation with $30 \% \mathrm{wt} / \mathrm{vol}$ ammonium sulphate at $8^{\circ} \mathrm{C}$, and molecular exclusion chromatography using the standard protocol. Histidine-tag was removed from the recombinant proteins by digesting with Factor Xa protease followed by passing through Ni affinity column. The absence of his-tag in the protein eluted in flow-through fraction was confirmed using poly histidine antibodies and the concentration was determined by taking OD at $280 \mathrm{~nm}$ in NanoDrop (Synergy H1 Hybrid Multi-Mode Reader Biotek).

\section{DNA-protein interaction studies}

DNA binding activity of DnaA, ParB2, and ParB3 was monitored using electrophoretic mobility shift assay as described earlier (Charaka \& Misra, 2012; Maurya et al, 2019a) with different versions of cis-element as DNA substrates. In brief, the full-length cisll and cisMP and their repeat derivatives (Fig S4A and B) were PCR-amplified using sequence-specific primers (Table S1) except the two repeats and one repeat that were chemically synthesized and annealed with the complementary strand. The $\left[{ }^{32} \mathrm{P}\right]$ labeled DNA probes were used for DNA binding assay. For the competition assay, saturating concentrations of DnaA or ParBs with radiolabelled DNA substrates were chased with different concentrations of unlabeled nonspecific DNA (NS-DNA) of similar length (Table S1) and a 10-fold higher concentration of same unlabeled cis sequence. The products were resolved on $6-10 \%$ native PAGE gel as required. The DNA band intensity was determined densitometrically using Image J software, and the fractions of bound DNA were plotted against different protein concentrations using GraphPad Prism 5. The Kd value for the curve fitting of individual plots was determined.

\section{Construction of deletion mutants and cell survival studies}

The constructs for generating knockout of both cis-elements were made in pNOKOUT plasmid as described earlier (Khairnar et al, 2008). In brief, 500 bps upstream and $~ 500$ bps downstream fragments to the cisll and cisMP were PCR amplified with the primers (Table S1) and cloned at KpnI/ECoRI and BamHI/Xbal sites in pNOKOUT plasmid to yield pNOKCII and pNOKCM plasmids, respectively (Table S2). These plasmids were linearized with Xmnl and transformed into $D$. radiodurans cells. The homozygous replacement of cisll and cisMP by nptll was achieved through several rounds of sub-culturing and then ascertained by diagnostic PCR using flanking primers (Table S1 and Fig S2A-C). The confirmed mutant cells were maintained in the absence of selection pressure but ensured for antibiotic resistance before the experiments.

The survival of $\triangle c i s / l$ and $\triangle$ cisMP deletion mutants was monitored under normal conditions and in response to different doses of $y$ radiation as described earlier (Misra et al, 2006). In brief, the cells were grown in the absence and presence of antibiotics. These cells were plated on TGY agar plate with and without antibiotics under normal conditions. These cells were independently exposed to different doses of $y$-radiation $(2,4,6$, and $9 \mathrm{kGy})$ at the dose rate of $1.81 \mathrm{kGy} / \mathrm{h}$ using Gamma Cell 5000 irradiator $\left({ }^{60} \mathrm{Co}\right.$; Board of Radiation and Isotopes Technology, DAE). The equal number of irradiated cells and their SHAM controls were washed in PBS and the different dilutions were plated in replicates on TGY agar plates with antibiotics, as required. The plates were incubated at $32^{\circ} \mathrm{C}$ for 45-48 $\mathrm{h}$ and CFUs were counted.

\section{Estimation of genome copy number}

The copy number of genomic replicon and mini replicons like pNOKcisll and pNOKcisMP was determined in the exponentially growing $D$. radiodurans cells using modified protocols of Breuert et al (2006) as described earlier in Maurya et al (2019a). In brief, the density and cell numbers of the independent sample were 
normalized for a fixed OD $600 \mathrm{~nm}$ and by CFUs. These cells lysed in buffer containing $10 \mathrm{mM}$ Tris, $\mathrm{pH}$ 7.6, $1 \mathrm{mM}$ EDTA, and $4 \mathrm{mg} / \mathrm{ml}$ lysozyme followed by repeated cycles of freezing and thawing. The clear cell-free extract was used for quantitative Real-Time PCR. The qPCR analysis involves three different genes of similar PCR efficiency from each genomic replicon of $D$. radiodurans. For instance, ftsE, ftsK, and ftsZ for chromosome I; DR_A0155, DR_A0182, and pprA for chromosome II; DR_B0003, DR_B0030, and DR_B0104 for megaplasmid and DR_C0001, DR_C0018, and DR_C0034 for small plasmid (Table S1). For mini replicons, the $n p t I I\left(\operatorname{Kan}^{\mathrm{R}}\right)$ and bla $\left(\mathrm{Amp}^{\mathrm{R}}\right)$ genes of plasmid backbones (Table S1) were used for copy number determination. The 300 bp PCR amplified DNA fragments were quantified by nanodrop and DNA concentrations were calculated using the molecular mass computed with "oligo calc" (www.basic.northwestern.edu/biotools). A serial dilution was made for each standard fragment and GPCR was carried out by following the MIQE guidelines using Roche Light cycler (Bustin et al, 2009) and the cycle threshold (Ct) values were determined. The copy number of each replicon is quantified by comparing the results with a standard plot. The average copy number reflected from all three genes per replicon was analysed using statistical analysis of the data obtained from the three independent biologic replicates for each sample.

\section{Construction of teto insertion derivatives of the genomic replicons in $D$. radiodurans}

The 240 repeats of tetO operator cassette from pLAU44 plasmid (Lau et al, 2003) were integrated near the putative "origin of replication" at $1.5^{\circ}$ in $\mathrm{Chrl}, 4^{\circ}$ in Chrll, and $4.5^{\circ}$ in MP of the circular map of these replicons in $D$. radiodurans. For that, the PCR amplifications of $10,713-11,715$ bp region corresponding to $1.5^{\circ}$ of $\mathrm{Chrl}$ using $\mathrm{Chrl}\left(1.5^{\circ}\right)$ Fw and $\mathrm{Chrl}\left(1.5^{\circ}\right) \mathrm{Rw}$ primers, 4659-c5691 bp region corresponding to $4^{\circ}$ of Chrll using $\mathrm{Chrll}\left(4^{\circ}\right) \mathrm{Fw}$ and $\mathrm{Chrll}\left(4^{\circ}\right) \mathrm{Rw}$ primers, and 2,203-3,000 bp region corresponding to $4.5^{\circ}$ of MP using Mp (4.5 $)$ Fw and $M p\left(4.5^{\circ}\right)$ Rw were carried out. These PCR fragments were cloned in pLAU44 at Xbal-Scal sites to yield p44Ch1, p44Ch2 and p44MP plasmids having homologous sequences of Chrl, Chrll, and MP, respectively. Furthermore, an expressing cassette of spectinomycin resistance gene was amplified from pVHS559 (Charaka \& Misra, 2012) using SpecFw and SpecRw primers and cloned at Nhel-Xhol sites in p44Ch1, p44Ch2, and p44MP to give p44SCh1, p44SCh2, and p44SMP, respectively. These constructs were confirmed by restriction digestion, PCR and DNA sequencing. The p44SCh1, p44SCh2, and p44SMP plasmids were separately transformed into wild type, and $\triangle c i s / l$ and $\triangle$ cisMP mutants of $D$. radiodurans. The transformants were scored under antibiotics selection and the homogenous insertion of tetO repeats in the genome was achieved through several rounds of subculturing. This was ascertained by diagnostic PCR using different sets of primers (Table S1). The resultant strains of $D$. radiodurans were named with suffix as R1::Chrl-tetO, R1::Chrll-tetO, R1::MP-tetO, $\Delta$ cisll::Chrl-tetO, $\Delta$ cisll::Chrll-tetO, $\Delta$ cisll::MP-tetO, $\Delta$ cisMP::Chrl-tetO, $\triangle$ cisMP:::Chrll-tetO, and $\triangle$ cisMP:::MP-tetO as listed in Table S2.

\section{Construction of TetR-GFP expression plasmid in D. radiodurans}

The coding sequence of tetR was PCR amplified from pLAU53 (Lau et al, 2003) using gene-specific primers (Table S1) and cloned at Sacl and Sall sites in pDSW208 (Weiss et al, 1999) to give pDTRGFP plasmid. Furthermore, tetR-gfp was PCR amplified from pDTRGFP plasmid using TetRscIApIFw and GFPXbalRw primers and cloned in pRADgro (Khairnar et al, 2008) at Apal-Xbal sites to produce pRADTRGFP (Table S2). The constitutive expression of TetR-GFP from pRADTRGFP plasmid in D. radiodurans was confirmed by fluorescence microscopy and the Western blotting using anti-GFP antibodies (Fig S5A and B). The tetO operator containing cells of $D$. radiodurans $\mathrm{R} 1, \triangle$ cis $/$ and $\triangle$ cisMP mutants (Table S2) expressing TetR-GFP on pRADTRGFP plasmid were observed under a fluorescence microscope as described earlier (Maurya et al, 2019a). In brief, overnight (14 h) grown cultures were harvested, washed with PBS and stained with DAPI (4',6-diamidino-2-phenylindole, dihydrochloride; $0.2 \mathrm{mg} / \mathrm{ml}$ ) for nucleoid and Nile red $(1 \mathrm{mg} / \mathrm{ml})$ for membrane. These samples were imaged through differential interference contrast, DAPI, FITC, and TRITC channels under an inverted fluorescence microscope (Olympus IX83) fitted with an Olympus DP80 CCD monochrome camera. The images were aligned and processed using inbuilt software "CellSens." A population of $\sim 200$ cells was analysed for results and data were presented as a scattered plot. One representative image belonging to more than $90 \%$ population is presented separately as differential interference contrast, DAPI, Nile Red, and GFP and merged of all these. Experiments were repeated independently to ensure the reproducibility and significance of these data.

\section{Data Availability}

This article contains data that have been recorded using lowthroughput technologies and are available anytime for cross references.

\section{Supplementary Information}

Supplementary Information is available at https://doi.org/10.26508/lsa. 202000856.

\section{Acknowledgements}

The authors are grateful to Dr SK Apte for his comment on the work and results, and Dr Swathi Kota, Dr YS Rajpurohit, and Dr Sheetal Uppal for their technical inputs. The authors also thank Ms Shruti Mishra and Ms Reema Chaudhary for reading through the manuscript, their comments, and help in fluorescence imaging. GK Maurya is grateful to the Department of Atomic Energy, India, for the research fellowship.

\section{Author Contributions}

GK Maurya: conceptualization, resources, data curation, formal analysis, investigation, methodology, and writing-original draft, review, and editing. 
HS Misra: conceptualization, resources, data curation, formal analysis, supervision, funding acquisition, validation, investigation, visualization, methodology, project administration, and writing-original draft, review, and editing.

\section{Conflict of Interest Statement}

The authors declare that they have no conflict of interest.

\section{References}

Badrinarayanan A, Le TB, Laub MT (2015) Bacterial chromosome organization and segregation. Annu Rev Cell Dev Biol 31: 171-199. doi:10.1146/ annurev-cellbio-100814-125211

Balson DF, Shaw WV (1990) Nucleotide sequence of the rep gene of staphylococcal plasmid pCW7. Plasmid 24: 74-80. doi:10.1016/0147619x(90)90027-a

Ben-Yehuda S, Fujita M, Liu XS, Gorbatyuk B, Skoko D, Yan J, Marko JF, Liu JS, Eichenberger P, Rudner DZ, et al (2005) Defining a centromere-like element in Bacillus subtilis by identifying the binding sites for the chromosome-anchoring protein RacA. Mol Cell 17: 773-782. doi:10.1016/j.molcel.2005.02.023

Breuert S, Allers T, Spohn G, Soppa J (2006) Regulated polyploidy in Halophilic archaea. PLoS One 1: e92. doi:10.1371/journal.pone.0000092

Bustin SA, Benes V, Garson JA, Hellemans J, Huggett J, Kubista M, Mueller R, Nolan T, Pfaffl MW, Shipley GL, et al (2009) The MIQE guidelines: Minimum information for publication of quantitative real-time PCR experiments. Clin Chem 55: 611-622. doi:10.1373/clinchem.2008.112797

Cervantes-Rivera R, Pedraza-López F, Pérez-Segura G, Cevallos MA (2011) The replication origin of a repABC plasmid. BMC Microbiol 11: 158. doi:10.1186/1471-2180-11-158

Charaka VK, Misra HS (2012) Functional characterization of the role of the chromosome I partitioning system in genome segregation in Deinococcus radiodurans. J Bacteriol 194: 5739-5748. doi:10.1128/ jb.00610-12

Crooks GE, Hon G, Chandonia JM, Brenner SE (2004) WebLogo: A sequence logo generator. Genome Res 14: 1188-1190. doi:10.1101/gr.849004

Dame RT, Tark-Dame M (2016) Bacterial chromatin: Converging views a different scale. Curr Opin Cell Biol 40: 60-65. doi:10.1016/ j.ceb.2016.02.015

Das AD, Misra HS (2011) Characterization of DRA0282 from Deinococcus radiodurans for its role in bacterial resistance to DNA damage. Microbiology (Reading) 157: 2196-2205. doi:10.1099/mic.0.040436-0

Desai SS, Rajpurohit YS, Misra HS, Deobagkar DN (2011) Characterization of RadS/RadR two-component system role in radiation resistance of Deinococcus radiodurans. Microbiology (Reading) 157: 2974-2982. doi:10.1099/mic.0.049361-0

Dubarry N, Pasta F, Lane D (2006) ParABS systems of the four replicons of Burkholderia cenocepacia: New chromosome centromeres confer partition specificity. J Bacteriol 188: 1489-1496. doi:10.1128/ jb.188.4.1489-1496.2006

Dubarry N, Willis CR, Ball G, Lesterlin C, Armitage JP (2019) In vivo imaging of the segregation of the 2 chromosomes and the cell division proteins of Rhodobacter sphaeroides reveals an unexpected role for Mipz. mBio 10: e02515-e02518. doi:10.1128/mbio.02515-18

Egan ES, Waldor MK (2003) Distinct replication requirements for the two Vibrio cholerae chromosomes. Cell 114: 521-530. doi:10.1016/s00928674(03)00611-1
Esnault E, Valens M, Espéli O, Boccard F (2007) Chromosome structuringlimits genome plasticity in Escherichia coli. PLoS Genet 3: e226. doi:10.1371/ journal.pgen.0030226

Fisher JK, Bourniquel A, Witz G, Weiner B, Prentiss M, Kleckner N (2013) Fourdimensional imaging of $E$. coli nucleoid organization and dynamics in living cells. Cell 153: 882-895. doi:10.1016/j.cell.2013.04.006

Floc'h K, Françoise Lacroix F, Servant P, Wong Y-S, Kleman J-P, Bourgeois D, Timmins J (2019) Cell morphology and nucleoid dynamics in dividing Deinococcus radiodurans. Nat Commun 10: 1-13. doi:10.1038/s41467019-11725-5

Fogel MA, Waldor MK (2005) Distinct segregation dynamics of the two Vibrio cholerae chromosomes. Mol Microbiol 55: 125-136. doi:10.1111/j.1365$2958.2004 .04379 x$

Galardini M, Pini F, Bazzicalupo M, Biondi EG, Mengoni A (2013) Replicon-dependent bacterial genome evolution: The case of Sinorhizobium meliloti. Genome Biol Evol 5: 542-558. doi:10.1093/gbe/evt027

Gerdes K, Howard M, Szardenings F (2010) Pushing and pulling in prokaryotic DNA segregation. Cell 121: 927-942. doi:10.1016/j.cell.2010.05.033

Ghosh S, Grove A (2006) The Deinococcus radiodurans-encoded HU protein has two DNA-binding domains. Biochemistry 45: 1723-1733. doi:10.1021/bi0514010

Green MR, Sambrook J (2012) Molecular Cloning: A Laboratory Manual. New York: Cold Spring Harbor Laboratory Press.

Harsojo KS, Matsuyama A (1981) Genome multiplicity and radiation resistance in Micrococcus radiodurans. J Biochem 90: 877-880. doi:10.1093/oxfordjournals.jbchem.a133544

Hassan AK, Moriya S, Ogura M, Tanaka T, Kawamura F, Ogasawara N (1997) Suppression of initiation defects of chromosome replication in Bacillus subtilis dnaA and oric-deleted mutants by integration of a plasmid replicon into the chromosomes. J Bacteriol 179: 2494-2502. doi:10.1128/jb.179.8.2494-2502.1997

Hayes F, Barillà D (2006) The bacterial segrosome: A dynamic nucleoprotein machine for DNA trafficking and segregation. Nat Rev Microbiol 4: 133-143. doi:10.1038/nrmicro1342

Holden MT, Titball RW, Peacock SJ, Cerdeno-Tarraga AM, Atkins T, Crossman LC, Pitt T, Churcher C, Mungall K, Bentley SD, et al (2004) Genomic plasticity of the causative agent of melioidosis, Burkholderia pseudomallei. Proc Natl Acad Sci U S A 101: 14240-14245. doi:10.1073/ pnas.0403302101

Kadoya R, Baek JH, Sarker A, Chattoraj DK (2011) Participation of chromosome segregation protein ParAl of Vibrio cholerae in chromosome replication. J Bacteriol 193: 1504-1514. doi:10.1128/ jb.01067-10

Kemter FS, Messerschmidt SJ, Schallopp N, Sobetzko P, Lang E, Bunk B, Sproer C, Teschler JK, Yildiz FH, Overmann J (2018) Synchronous termination of replication of the two chromosomes is an evolutionary selected feature in Vibrionaceae. PLoS Genet 14: e1007251. doi:10.1371/ journal.pgen.100725

Khairnar NP, Kamble VA, Misra HS (2008) RecBC enzyme overproduction affects UV and $y$ - radiation survival of Deinococcus radiodurans. DNA Repair 7: 40-47. doi:10.1016/j.dnarep.2007.07.007

Kjos M, Veening JW (2017) Tracking of chromosome dynamics in live Streptococcus pneumoniae reveals that transcription promotes chromosome segregation. Mol Microbiol 91: 1088-1105. doi:10.1111/ mmi.12517

Kota S, Kamble VA, Rajpurohit YS, Misra HS (2010) ATP-type DNA ligase requires other proteins for its activity in vitroand its operon components for radiation resistance in Deinococcus radiodurans in vivo. Biochem Cell Biol 88: 783-790. doi:10.1139/010-075

Lau IF, Filipe SR, Sфballe B, Økstad OA, Barre FX, Sherratt DJ (2003) Spatial and temporal organization of replicating Escherichia 
coli chromosomes. Mol Microbiol 49: 731-743. doi:10.1046/j.13652958.2003.03640.x

Le TB, Imakaev MV, Mirny LA, Laub MT (2013) High-resolution mapping of the spatial organization of a bacterial chromosome. Science 342: 731-734. doi:10.1126/science.1242059

Levin-Zaidman S, Englander J, Shimoni E, Sharma AK, Minton KW, Minsky A (2003) Ring like structure of the Deinococcus radiodurans genome: A key to radioresistance? Science 299: 254-256. doi:10.1126/ science. 1077865

Livny J, Yamaichi Y, Waldor MK (2007) Distribution of centromere-like parS sites in bacteria: Insights from comparative genomics. J Bacteriol 189: 8693-8703. doi:10.1128/jb.01239-07

Luo H, Gao F (2019) Doric 10.0: An updated database of replication origins in prokaryotic genomes including chromosomes and plasmids. Nucleic Acid Res 47: D74-D77. doi:10.1093/nar/gky1014

Marczynski G, Petit K, Patel P (2019) Crosstalk regulation between bacterial chromosome replication and chromosome partitioning. Front Microbiol 10: 279. doi:10.3389/fmicb.2019.00279

Marczynski GT, Shapiro L (1992) Cell-cycle control of cloned chromosomal origin of replication from Caulobacter crescentus. J Mol Biol 226: 959-977. doi:10.1016/0022-2836(92)91045-q

Maurya GK, Kota S, Kumar NN, Tewari R, Misra HS (2019a) ParA proteins of secondary genome elements crosstalk and regulate radioresistance through genome copy number reduction in Deinococcus radiodurans. Biochem J 476: 909-930. doi:10.1042/BC/20180799

Maurya GK, Kota S, Misra HS (2019b) Characterisation of ParB encoded on multipartite genome in Deinococcus radiodurans and their roles in radioresistance. Microbiol Res 223: 22-32. doi:10.1016/ j.micres.2019.03.005

Maurya GK, Misra HS (2020) PprA interacts with replication proteins and affects their physicochemical properties required for replication initiation in Deinococcus radiodurans. BioRxiv doi:10.1101/ 2020.03.25.007906Preprint posted March 28, 2020.

McHenry CS (2011) Bacterial replicases and related polymerases. Curr Opin Chem Biol 15: 587-594. doi:10.1016/j.cbpa.2011.07.018

Meima R, Lidstrom ME (2000) Characterization of the minimal replicon of a cryptic Deinococcus radiodurans SARK plasmid and development of versatile Escherichia coli-D. radiodurans shuttle vectors. Appl Environ Microbiol 66: 3856-3867. doi:10.1128/aem.66.9.3856-3867.2000

Messer W (2002) The bacterial replication initiator DnaA. DnaA and oric, the bacterial mode to initiate DNA replication. FEMS Microbiol Rev 26: 355-374. doi:10.1016/s0168-6445(02)00127-4

Minsky A, Shimoni E, Englander J (2006) Ring-like nucleoids and DNA repair through error-free nonhomologous end joining in Deinococcus radiodurans. I Bacteriol 188: 6047-6051. doi:10.1128/jb.01951-05

Misra HS, Khairnar NP, Kota S, Srivastava S, Joshi VP, Apte SK (2006) An exonuclease I sensitive DNA repair pathways in Deinococcus radiodurans: A major determinant of radiation resistance. $\mathrm{Mol}$ Microbiol 59: 1308-1316. doi:10.1111/j.1365-2958.2005.05005.x

Misra HS, Rajpurohit YS, Kota S (2013) Physiological and molecular basis of extreme radioresistance in Deinococcus radiodurans. Curr Sci 104: 194-205.

Misra HS, Maurya GK, Kota S, Charaka VK (2018) Maintenance of multipartite genome system and its functional significance in bacteria. J Genet 97: 1013-1038. doi:10.1007/s12041-018-0969-x

Morikawa K, Ohniwa RL, Kim J, Maruyama A, Ohta T, Takeyasu K (2006) Bacterial nucleoid dynamics: Oxidative stress response in Staphylococcus aureus. Genes Cells 11: 409-423. doi:10.1111/j.13652443.2006.00949.x

Morikawa K, Ushijima Y, Ohniwa RL, Miyakoshi M, Takeyasu K (2019) What happens in the staphylococcal nucleoid under oxidative stress? Microorganisms 7: 631. doi:10.3390/microorganisms7120631
Murray H, Errington J (2008) Dynamic control of the DNA replication initiation protein DnaA by Soj/ParA. Cell 135: 74-84. doi:10.1016/j.cell.2008.07.044

Narumi I, Satoh K, Cui S, Funayama T, Kitayama S, Watanabe H (2004) PprA: A novel protein from Deinococcus radiodurans that stimulates DNA ligation. Mol Microbiol 54: 278-285. doi:10.1111/j.13652958.2004.04272.x

Ogasawara N, Moriya S, von Meyenburg K, Hansen FG, Yoshikawa H (1985) Conservation of genes and their organization in the chromosomal replication origin region of Bacillus subtilis and Escherichia coli. EMBO J 4: 3345-3350. doi:10.1002/j.1460-2075.1985.tb04087.x

Okumura T, Makiguchi H, Makita Y, Yamashita R, Nakai K (2007) Melina II: A web tool for comparisons among several predictive algorithms to find potential motifs from promoter regions. Nucleic Acid Res 35: W227-W231. doi:10.1093/nar/gkm362

Pal D, Venkova-Canova T, Srivastava P, Chattoraj DK (2005) Multipartite regulation of rctB, the replication initiator gene of Vibrio cholerae chromosome II. J Bacteriol 187: 7167-7175. doi:10.1128/jb.187.21.71677175.2005

Pinto UM, Flores-Mireles AL, Costa ED, Winans SC (2011) RepC protein of the octopine-type Ti plasmid binds to the probable origin of replication within repC and functions only in cis. Mol Microbiol 81: 1593-1606. doi:10.1111/j.1365-2958.2011.07789.x

Pinto U, Pappas K, Winans S (2012) The ABCs of plasmid replication and segregation. Nat Rev Microbiol 10: 755-765. doi:10.1038/nrmicro2882

Pióro M, Jakimowicz D (2020) Chromosome segregation proteins as coordinators of cell cycle in response to environmental conditions. Front Microbiol 11: 588. doi:10.3389/fmicb.2020.00588

Pogliano J, Ho TQ, Zhong Z, Helinski DR (2001) Multicopy plasmids are clustered and localized in Escherichia coli. Proc Natl Acad Sci U S A 98 4486-4491. doi:10.1073/pnas.081075798

Qin MH, Madiraju MVVS, Rajagopalan M (1999) Characterization of the functional replication origin of Mycobacterium tuberculosis. Gene 233: 121-130. doi:10.1016/s0378-1119(99)00148-1

Rajpurohit YS, Misra HS (2010) Characterization of a DNA damage-inducible membrane protein kinase from Deinococcus radiodurans and its role in bacterial radioresistance and DNA strand break repair. Mol Microbiol 77: 1470-1482. doi:10.1111/j.1365-2958.2010.07301.x

Rasmussen T, Jensen RB, Skovgaard O (2007) The two chromosomes of Vibrio cholerae are initiated at different time points in the cell cycle. EMBO J 26: 3124-3131. doi:10.1038/sj.emboj.7601747

Reyes-Lamothe R, Nicolas E, Sherratt DJ (2012) Chromosome replication and segregation in bacteria. Ann Rev Genet 46: 121-143. doi:10.1146/ annurev-genet-110711-155421

Richardson TT, Harran O, Murray H (2016) The bacterial DnaA-trio replication origin element specifies single-stranded DNA initiator binding. Nature 534: 412-416. doi:10.1038/nature17962

Richardson TT, Stevens D, Pelliciari S, Harran O, Sperlea T, Murray H (2019) Identification of a basal system for unwinding a bacterial chromosome origin. EMBO J 38: e101649. doi:10.15252/embj.2019101649

Scholefield G, Whiting R, Errington J, Murray H (2011) Spo0) regulate the oligomeric state of Soj to trigger its switch from an activator to an inhibitor of DNA replication initiation. Mol Microbiol 79: 1089-1100. doi:10.1111/j.1365-2958.2010.07507.x

Tanaka T, Ishida H, Maehara T (2005) Characterization of the replication region of plasmid pLS32 from the Natto strain of Bacillus subtilis. J Bacteriol 187: 4315-4326. doi:10.1128/jb.187.13.4315-4326.2005

Thanbichler M, Shapiro L (2006) MipZ, a spatial regulator coordinating chromosome segregation with cell division in Caulobacter. Cell 126: 147-162. doi:10.1016/j.cell.2006.05.038

Tougu K, Marians KJ (1996) The interaction between helicase and primase sets the replication fork clock. J Biol Chem 271: 21398-21405. doi:10.1074/jbc.271.35.21398 
Vecchiarelli AG, Han Y-W, Tan X, Mizuuchi M, Ghirlando R, Biertümpfel C, Funnell BE, Mizuuchi K (2010) ATP control of dynamic P1 ParA-DNA interactions: A key role for the nucleoid in plasmid partition. Mol Microbiol 78: 78-91. doi:10.1111/j.1365-2958.2010.07314.X

Venkova-Canova T, Baek JH, Fitzgerald PC, Blokesch M, Chattoraj DK (2013) Evidence for two different regulatory mechanisms linking replication and segregation of Vibrio cholerae chromosome II. PLoS Genet 9: e1003579. doi:10.1371/journal.pgen.1003579

Weiss DS, Chen JC, Ghigo JM, Boyd D, Beckwith J (1999) Localization of FtsI (PBP3) to the septal ring requires its membrane anchor, the $\mathrm{Z}$ ring, FtsA, FtsQ, and FtsL. J Bacteriol 181: 508-520. doi:10.1128/jb.181.2.508-520.1999

Weitao T, Dasgupta S, Nordström K (2000) Plasmid R1 is present as clusters in the cells of Escherichia coli. Plasmid 43: 200-204. doi:10.1006/plas.1999.1457
White O, Eisen JA, Heidelberg JF, Hickey EK, Peterson JD, Dodson RJ, Haft DH, Gwinn ML, Nelson WC, Richardson DL, et al (1999) Genome sequence of the radioresistant bacterium Deinococcus radiodurans R1. Science 286: 1571-1577. doi:10.1126/science.286.5444.1571

Yamaichi Y, Bruckner R, Ringgaard S, Möll A, Cameron DE, Briegel A, Jensen GJ, Davis BM, Waldor MK (2012) A multidomain hub anchors the chromosome segregat and chemotactic machinery to the bacterial pole. Genes Dev 26: 2348-2360. doi:10.1101/gad.199869.112

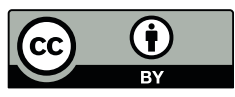

License: This article is available under a Creative Commons License (Attribution 4.0 International, as described at https://creativecommons.org/ licenses/by/4.0/). 